\title{
THE INCORPORATED
}

\section{INSTITUTION OF AUTOMOBILE ENGINEERS.}

\section{The Composition of Commercial Petrols.}

By BERTRAM BLOUNT, F.I.C.

From the time when the motor car in its modern form came into use, the nature of the fuel has, in some degree, occupied the minds of the user, though probably to a smaller extent than his interests demanded. In the early days of the modern period-from 1896 onwards--some attempt was made to test the quality of the petrol of that date by taking its specific gravity with an hydrometer. It was soon found that this test by itself was of little value, and with the advent of the practice of delivering petrol in sealed cans most users were content to accept the material supplied them on the strength of the brand. I confess that, although in the course of my motoring experience $I$ must at a moderate computation have bought and burned about ten tons of petrol, I have limited my examination to samples sent me professionally, and have made no endeavour to control the quality of my own purehases. But the suggestion of your President, coupled with the fact that large users now require the material they buy to comply with a given standard, and in consequence need a specification defining the quality, has led me to examine systematically some of the leading makes in order to ascertain what variations oceur and what limits may be laid down in fairness to the maker, and for the protection of the consumer.

I think it may safely be asserted that in the minds of many users, especially those of private owners, there has been a lurking doubt whether the petrol they obtain of any given brand is uniform and uniformly good. A car from causes too numerous to mention may be behaving well or ill, and in the difficulty of deciding what is 
the true source of its caprices, it is not unnatural to assume that the petrol is to blame. Nor is this attitude unreasonable, for there is little doubt that alterations of quality have taken place from time to time, some of which may not have been for the better. I do not propose to go into this historical aspect of the question, but to endeavour to show what is the present condition of things.

For this purpose I caused to be procured samples of seven different brands. In all but one case two or more specimens of each were obtained. They were all bought in London, but at different shops or garnges-- some magnificent and others humble. No intimation of the intended use was givet, and all the cans were properly sealed. It may fairly be taken that the petrol was such as the producers habitually make.

The samples were examined by the usual process of fractional distillation, and their specific gravities and those of their fractions were determined. In addition, a certain number were analysed for their content of sulphur, and one or more examples of each brand were burnt in a calorimeter.

The whole of these results are shown in the accompanying table.

I will deal with the last-named item first-that is, the calorific value. It is often supposed that this varies a good deal with petrol of different origin or quality, but in fact the variations are small, as can be seen from the figures in the table. This, of course, refers to the calorific value of a given weight of the fuel; when comparison is made by volume there is a considerable difference owing to the difference in specific gravity of petrols of different origin. The calorific value stated in calories per litre and in B.T.U. per ${ }^{1} \frac{1}{5}$ th of a gallon indicate this, and go to show that as long as petrol is sold by measure instead of weight an appreciable advantago is secured by buying the heavier grades, always provided that they can be burnt as efficiently.

The determination of the calorific value was a matter of some little difficulty. A bomb calorimeter was used which, though easy enough to manipulate when solid fuels are burnt, needs special handling with a volatile liquid like petrol. In spite of the fact that there is an ample excess of oxygen at a pressure of 25 atmospheres in the bomb, complete combustion was difficult to secure. Moreover, the explosion was so violent as to shatter the platinum eup in which the petrol was contained. After many trials a device due to Berthelot was adopted. The petrol was enclosed in a relatively deep cup provided with a celluloid envelope 
TABLE shocing the Results of an Examination, by the usual. process of Fractional Distillation, of Samples of Seven different Brands of Petrot.

[T' face page 302.

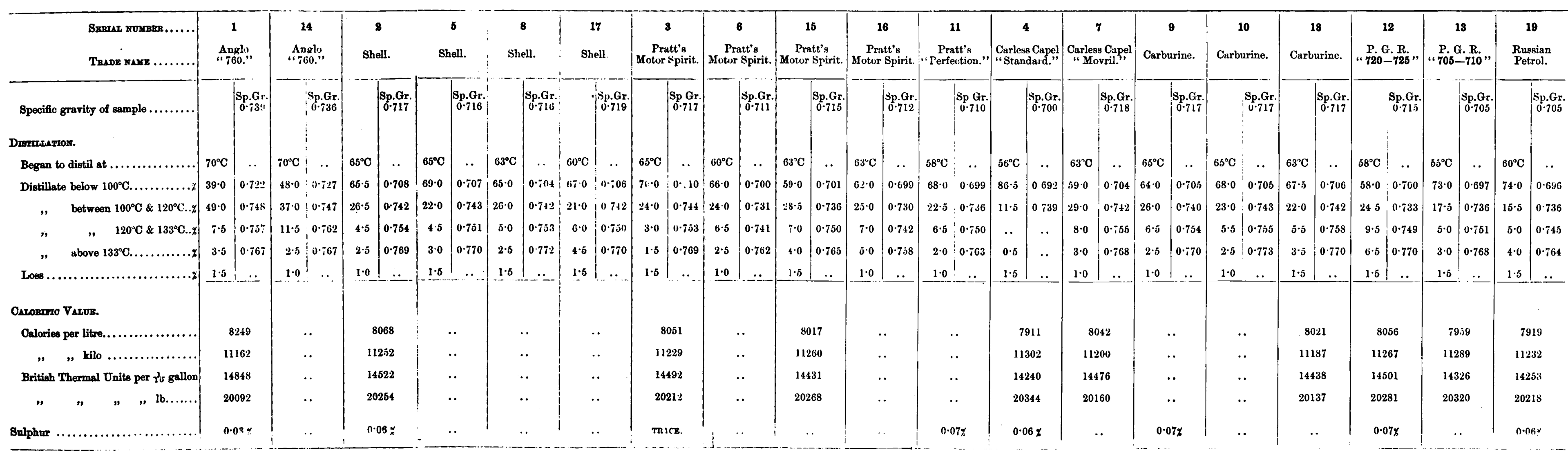


rising above the edge of the cup and contracted at the top so as to form a sort of sack with a relatively narrow mouth. By this means the vapour was confined sufficiently to cause it to burn at a moderate rate, and imperfect combustion and violent explosions were avoided. A small correction is made for the heat of combustion of the celluloid shell.

The percentage of sulphur in all cases is so small as to be without practical significance. Whatever may be the faults of the petrol engine, it is free from the drawback which occurs with all engines in which the fuel is coal.

The remaining figures, and especially those of the fractionation, are worthy of a little study. It may be noticed that the specific gravity of any given brand, though not constant, varies within comparatively narrow limits, save, of course, "in cases where there are two grades of each brand. The percentages distilling within given limits are in some cases less regular, but on the whole the variations are moderate, and not greater than might be expected with a commodity which from its origin is not a single substance, but a very complex mixture, whose constituents will vary on account of small alterations of condition of manufacture.

Three of the brands present so general a similarity that they may be conveniently grouped and their average fractional composition compared.

Average.

Pratt.

Shell. Carburine. Per cent. by volume.

\begin{tabular}{rrrrrr} 
Below $100^{\circ} \mathrm{C} \ldots \ldots$ & $65 \cdot 0$ & $\ldots$ & $66 \cdot 6$ & $\ldots$ & $66 \cdot 5$ \\
$100-120^{\circ} \mathrm{C} . \ldots \ldots$ & $24 \cdot 8$ & $\ldots$ & $23 \cdot 9$ & $\ldots$ & $23 \cdot 7$ \\
$120-133^{\circ} \mathrm{C} . \ldots \ldots$ & $6 \cdot 0$ & $\ldots$ & $5 \cdot 0$ & $\ldots$ & $5 \cdot 8$ \\
Above $133^{\circ} \mathrm{C} \ldots \ldots$ & $3 \cdot 0$ & $\ldots$ & $3 \cdot 1$ & $\ldots$ & $2 \cdot 8$ \\
Loss....... & $1 \cdot 2$ & $\ldots$ & $1 \cdot 4$ & $\ldots$ & $1 \cdot 2$ \\
\hline $100 \cdot 0$ & $\ldots$ & $100 \cdot 0$ & $\ldots$ & $100 \cdot 0$
\end{tabular}

The resemblance is sufficiently close to make it perfectly possible to draft a specification for petrol of this grade which could be fulfilled by all three brands, thus freeing the consumer from the obligation to buy any particular one. It may reasonably be accepted that in practice but little difference will be found in their behaviour, and that each may be employed equally successfully as cheapness or convenience may dictate.

The other brands differ too widely to admit of useful grouping, but comments on two or three may be permitted. Anglo "760," 
which actually has a specific gravity of $735-740$, is in a class by itself. It differs from the foregoing chiefly in the smaller fraction distilling below 100 deg. $\mathrm{C}$., and by the large middle fraction distilling between 100 and $120 \mathrm{deg}$. O. The succesding fraction, from 120 to $133 \mathrm{deg}$. C., is comparatively large, as might be expected, but it is worthy of note that the tailings in the true sense (distillate above $133 \mathrm{deg}$. C.) are quite as small as those of the three brands already discussed. The other sample which needs special mention is Carless's "standard." This is considerably the lightest of those examined, 86.5 per cent. distilling below 100 deg. O., and 98 per cent. below 120 deg. O. Like Anglo " 760 ," but at the other end of the scale, it stands in a class by itself, and probably is similar to the petrol of earlier days, when 0.680 was desired as a standard of specific gravity, and 0.700 was regarded rather as an upper than a lower limit. It is quite evident that if petrol of this class is required, a very different specification from that which is satisfied by the brands already referred to would be necessary.

It is not easy to provide a good peroration to a paper which is chiefly a tabulated record of facts, and without attempting that feat I may simply say that, as far as can be judged from the moderate number of samples examined, petrol of recognised brands is fairly uniform in quality, that there is no great difference between three of these recognised brands, but there are certain others of equal standing which are sharply differentiated from the foregoing. That these facts must be borne in mind when drafting any specification which is designed to ensure obtaining a wished-for grade, and at the same time is not drawn in such narrow terms as to tie the purchaser to any particular make, to the exclusion of others which may serve his purpose equally well.

The experimental work for this paper has been carried out by two of my assistants, Mr. Mellersh and Mr. Course, whose zeal and care I acknowledge with great pleasure. 


\section{THE DISOUSSION.}

Mr. Buount, in opening the discussion, said : Mr. Ballantyne's paper bristles with interest, and some of the things that have been brought out in it, although they are matters which should be generally known, seem to have been overlooked by most people connected with the motor industry. For instance, the notion that picric acid in some way or other increases the power of the engine has been exploded by Mr. Ballantyne. Every chemist knows that the notion has no foundation in fact, but many people still eling to that idea. It is fitting, therefore, that it should have come to the lot of Mr. Ballantyne, speaking at a meeting of this Institution, to refute that notion, and $M r$. Ballantyne is to be congratulated on having nailed that lie to the counter.

As to his suggestion that a simplified method of gas analysis should be put into the hands of what he calls a " sensible employee," I cannot help thinking that it is a sort of self-denying ordinance. It is to my mind not well that this sort of work should be done by a glorified fitter, and to expect such a person to make an analysis is expecting rather too much, and I think not only from the point of view of the industry, but from his own point of view, Mr. Ballantyne is making a mistake.

It is gratifying to know that the proportion of carbon monoxide in the exhaust gases emitted from motor cars is going down.

Mr. G. H. BaILlie: I am very glad that the Institution has had the benefit of these two papers on the subject of petrol. It is a subject which is important to every class of user of motor cars, and the neglect that it has suffered is quite undeserved. To me, these two papers have been of particular interest, and I think that our President is to be congratulated upon having got to-night so strong a combination as Mr. Ballantyne and Mr. Blount, two authors who are perhaps better qualified than any others to speak upon the subject. I fully agree with Mr. Blount that Mr. Ballantyne has done a good service to the automobile world by exposing the bogey of picric acid. I always felt it was nonsense, but I have never been able to get hold of any definite information to rebut the evidence that was so often brought forward of engines having their power enormously increased by its use. I gather from what $M r$. Ballantyne 
306 THE INCORPORATED INSTITUTION OF AUTOMOBILE ENGINGERS.

says that picric acid can only get into the cylinder if the carburation. is bad, so that practically all the volatisation can be done in the cylinder; and if it does get in it does more harm than good.

Another point in. Mr. Ballantyne's paper referred to the formation

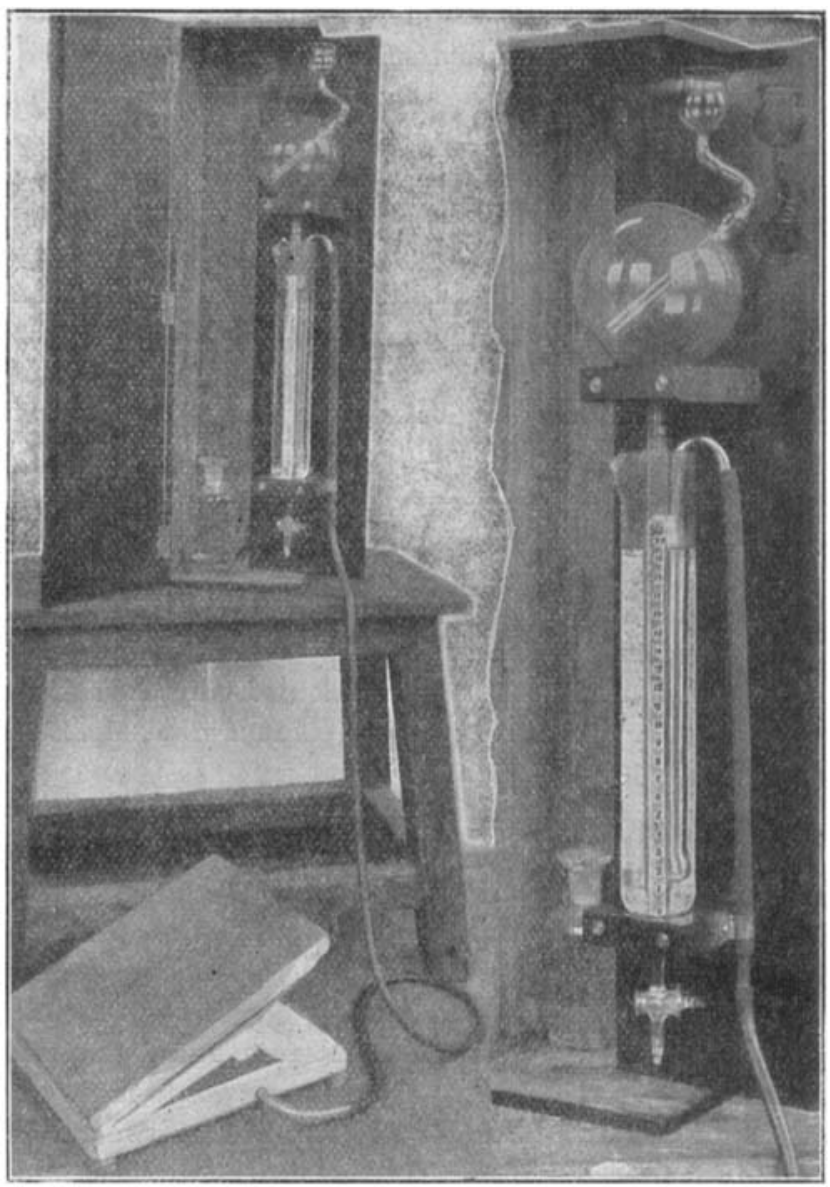

Composite Vinws of Bailuie's Fuel Temsting Apparatus.

Fira. 1.

of deposits of carbon upon the incomplete combustion of petrol. I read a paper at the Royal Automobile Club some time ago in which I said that too rich a mixture led to carbon deposits in the cylinder, and that this was the great objection to the use of heavy fuels. In 
the discussion which followed the reading of the paper, one gentleman, I forget whether it was Mr. Brewer or Mr. Duckham, said he had made experiments on the subject and found that petrol on a heated surface did not give rise to carbon deposits.

Both Mr. Brewer and Mr. Duckham are so well known that I could not suspect any error in their experiments, and yet $I \mathrm{know}$, and I suppose everyone else does too, of engines which have had carburettors giving too rich a mixture at low speeds and which do get a great deal of deposit in their cylinders. The question therefore puzzled me a good deal, and now Mr. Ballantyne has explained the matter in his paper, and has explained it with so much tact that Mr. Brewer, or Mr. Duckham, and I are now reconciled by his having told us that we were both right.

On one point I did not quite agree with Mr. Ballantyne. He said, I think, that there was no satisfactory progress to be made towards improved carburation unless by neans of an examination of the exhaust gases. I cannot help thinking that there is a better way. It is a way I have been working at for some time, so I may be prejudiced in its favour. I am endeavouring to get an air and. petrol meter, two meters which will measure, not the amount of air and the amount of petrol but their rates of flow. There are considerable difficulties in constructing these meters because of the very large rate of flow in the one case and the very small rate in the other. Given however, two meters of this kind joined on to the inlet side of the carburettor, it is possible to read off at once the proportions of air and petrol in the mixture and tell what the carburettor is doing. In that way one could carry out tests with carburation far more rapidly than would be possible with the exhaust gas analysis. I think, in fact, that the results would be so valuable that the apparatus is worth working out, and I sugges that it might be taken up by some of those present.

One very valuable part of Mr. Ballantyne's paper consists in the mothods he describes of testing petrol. I do not know of any methods given in the text books that are exactly like those he suggests. Some of the tests, as Mr. Blount says, can be far better done by Mr. Ballantyne himself, though others might certainly be done by laymen.

Turning now to Mr. Blount's paper, the figures he has given us are extremely interesting. The figures of the calorific value of the petrol bear out Dr. Watson's figures, and tell us, practically speaking, that all the petrols have the same calorific value. Purity I see is 
practically perfect in every case, and as a consequence we may say that the boiling point is the one characteristic of petrol that we want to know. In the paper I read last year that was the view I took, and I mentioned there an apparatus which I had worked out for testing this one characteristic. The characteristic, as I put it then, was the volatility of the petrol. Of course boiling point is one of the means of measuring the volatility. I have now got the apparatus in a commercial form, and as such it has been adopted by the Royal Automobile Club as the official testing apparatus for that body, and your President has asked me to show it to you now in its final form (see Fig. 1). My idea in working out this apparatus was not to volatilise the petrol at a high temperature, as is done in fractional distillation, but at ordinary temperatures as is done in the carburettor. It has an advantage over fractional distillation; for fractional distillation is a very laborious and difficult operation, and unless you have everything nicely prepared it is rather dangerous. The test under ordinary temperatures with this apparatus is very simple and perfectly safe. It has also the advantage that the measurement of the volatility enables one to compare different fuels, whereas by measuring the boiling points one can get no idea of their comparative value. As an example, alcohol has a boiling point of $78^{\circ}$, which is just lower than benzine, and lower than the greater part of the petrols of commerce, and yet cilcohol is only half as volatile as benzine or the greater portion of the petrol, so that the boiling point, when one is comparing alcohol, benzine, and petrol, is no guide at all. With this method, however, of ascertaining the volatility, one gets figures which do represent the relative volatilities and the relative value as substances to be used in carburettors.

The apparatus consists of a graduated tube terminating below in a stop-cock, and above in a large bulb with an opening to the air. Near the bottom of the tube a side tube is introduced, and is connected to a foot-bellows. The tube is filled with petrol, the quantity being read on the scale. Strokes of the bellows are given regularly and at intervals, which force the petrol up into the bulb and churn it up vigorously so as to evaporate it very rapidly. Each stroke of the bellows volatilises quite a considerable quantity of petrol. The arrangement of a double tube in the bulb is to save the petrol being carried off in suspension, and it took a good deal of trouble to find the shape of tube that avoided petrol going off, not as vapour, but as a liquid. With the arrangement as finally settled 
I find that no petrol at all is carried away in a liquid form. The level of the petrol is taken at the top, and the number of strokes of the bellows are taken as measuring the amount of air required to evaporate $\frac{x}{2} \frac{g}{0}$ ths of the whole volume of petrol. If one wishes to get a curve of the volatility of the petrol, one can take the intermediate readings. Of course, the temperature, and pressure, and the way the bellows are worked have a considerable effect upon the number of strokes required to evaporate a given amount of petrol, but all these conditions are eliminated by making the tests alwiays comparative. In the case, for instance, of desiring to test different deliveries of petrol under a contract, one would keep some of the first delivery and make comparative tests, comparing the first with the later deliveries. When samples are tested one after the other, all differences in this respect are entirely eliminated. The Royal Automobile Club has adopted heptane as the standard material with which fuels are to be compared. Heptane can be purchased fairly pure and quite cheaply. The air required to evaporate a certain amount of heptane is compared with the amount required to evaporate the sample of petrol. The whole apparatus was got out for a rough and practical test, and I was rather surprised to find the accuracy of which it was susceptible. If a certain amount of care is taken, one can get results accurate to within 1 per cent.

Mr. R. W. A. BReWER: I speak to-night on behalf of Mr. Duckham as well as myself. He expresses regret that he is not able to be present. In the first place I must take exception to the opening remarks of Mr. Ballantyne where he says that the present price of petrol is high. I do not consider that the price is unduly high. Mr. Duckham has gone into the whole subject and has given me some figures which set out the whole matter rather clearly. You may know that neither he nor I are interested in the sale of petrol in this country, and what he arrives at is as follows. Taking the case of the East Indies, whence we draw the greater part of our supplies, the cost of petrol distilled and refined cannot be less than $2 d$. per gallon. That petrol has to come 8,000 miles by ship and the ships have to go back again light. The cost of freight brings the item up certainly another $2 d$. per gallon. The heaviest item occurs when the petrol arrives here, and Mr. Duckham has very carefully gone into the cost of distribution, dilapidation of tins, \&c., and he brings that out at $3 \dot{d}$. a gallon in London and $4 \frac{1}{2} d$. per gallon in the provinces. So that if these figures are correct, the price at 
which it comes to the purchaser for delivery is about $7 d$. per gallon in London and $8 \frac{1}{2} d$. in the provinces. Mr. Duckham believes, and I agree with him, that on the evidence of these figures the prices charged in London are not excessive. Of course many of the larger suppliers do not really themselves own wells and have to purchase oil from other people, so that there is a margin of profit to be provided for to the distributing companies.

On the lower part of page 293, Mr. Ballantyne speaks about the cracking of oils. I have heard of processes, though how much truth there is in it I do not know, by which you can take ordinary paraffin and precipitate a wax, and produce a fuel suitable for motor cars. I should like to have the ideas of Mr. Blount and Mr. Ballantyne on the subject.

With regard to Mr. Ballantyne's remarks upon dissolved gases in petrol, of course the whole of that information, although very interesting, is purely academic. I do not know what advantage anyone will gain by trying to dissolve anything in petrol. I should try it, however, after the fuel left the tank and not in the tank. If one were going to try any other fuel, such as alcohol, and if one's idea were to mix acetylene gas with alcohol, it would be best to spray the liquid itself through a small $\operatorname{sieve}$, so that the action of the moisture present upon the calcium carbide could be made to produce gas, which would be carried forward, as the fuel came into contact with the carbide. I do not say that it would do any good at all if one carried out an achievement of that character.

Now with regard to the question of carbonaceous deposits, I wish to put in a word, and I may say that I am backed up by Mr. Duckham. On page 298 of the paper Mr. Ballantyne says, "The formation from petrol, or heavier petroleum spirits, of carbonaceous deposits in the cylinder, has sometimes puzzled experimenters, who have found that little or no deposit is produced when the fuel is dropped upors heated surfaces or led as vapour through heated tubes, and have therefore ascribed such deposits to lubricating oil in the cylinder." Mr. Duckham says that such carbonaceous deposits are attributed to the fuel rather than to the oil, but perhaps on this point he may have misunderstood the author. He would like to say that he has carried on a large number of experiments which clearly show that the amount of hard cake deposited varied with the amount of lubricating oil allowed in the cylinder; and further, that the higher the distillation point the largex the cake formed. The caking of the oil increases with the boiling point. Mr. Duckham 
bears out the theory that it is almost entirely due to the presence of lubricating oil. What he has found, and what I have found, is that the soot which is formed by incomplete combustion of the fuel does not deposit in the cylinders, but rather in the exhaust pipe and silencer. Ths reason he gives for that is, that the soot is formed in suspension in the gases which are expelled from the cylinder before it has time to settle. If you explode petrol vapour in a glass flask, the carbon takes a considerable time to settle down. I agree with Mr. Baillie that tests of volatility are more important from the motor users' point of view than tests of distillation. I do not deprecate tests of distillation in the least, but one finds out a great deal more from volatility tests. Some of my tests agree fairly well with Sorel's.

Mr. Blount has not mentioned the Borneo spirit as originally imported by the Shell people. It differed considerably from other spirits, so Mr. Duckham came to the conclusion (and we found out afterwards that our conclusions were fairly correct) that Borneo spirit had a large percentage of benzol in it. At the present time one notices the effect coming out in the Anglo results. The Anglo people do not like to state where they obtain their spirit from. I presume a good deal of it comes from Sumatra. That is not the same 760 spixit that we used to get in the early days when we purchased Borneo spirit. It has a different smell. It is a redistilled spirit. One cannot fail to notice that it varies considerably, as will be seen on referring to cols. 1 and 14 in Mr. Blount's table. In col. 14 the middle fraction is a very great one; so it is in col. 1 . In col. 1 the first series of distillates amount to 39 per cent. ; the middle series to 49 per cent. When you consider that this is supposed to be a similar spirit, bought under the same name, probably put up in the same cans, and sold as the same spirit, although probably from a different source, the result of the test is very different. The positions are reversed. In col. 14 the first series comes off as 48 per cent., the second series as 37 per cent.- so that that shows there is a want of uniformity in that particular spirit.

In conclusion, I would like to call attention to the fact that although Mr. Blount has tested some twenty samples that come from a large number of different sources, many of the samples being treated in different ways-although we cannot take these figures as hard and fast-we must agree at the same time that there is a great similarity between certain elasses of petrol, which 
points to the fact that a good many of them come from the same source, and would comply probably with the same specification.

Mr. W. J. Leonard: Mr. Blount's paper has given us a number of tests, and he says he has tested the spirit in the ordinary way, but he does not say what the ordinary way is. There is a good deal of difference in the methods of testing petroleum spirit. The ordinary commerciul method is to test it in a retort with a thermometer in the liquid. A great many scientific tests are carried out with the thermometer' in the vapour. The test varies according to the height of the tube, the length of the condenser, and the temperature at which the thing is done; and it is really most important for the author of the paper to carry his definition a little bit further. If he wishes to establish a standard method of testing he must enter more into detail. I might instance that the Admiralty have one test, the War Office have another, and the London County Council have quite another sort of test, and one is sometimes inclined to think that there are almost as many tests as there are specifications. You might also say that no two people conduct their tests in the same way. They vary very considerably, but that does not detract at all from the value of the figures given by $\mathrm{Mr}$. Blount, because they are comparative, and that is really what we want to know about them. If he would define them a little bit more it would be an advantage.

Mr. Ballantyne draws attention to the spirit which is got from condensation in the making of oil gas. I had a great deal to do with that twenty-five years ago. At that time benzol was worth about $5 s$. to $15 s$. per gallon. Now it is worth considerably less than 1s. The liquid was purchased from the Metropolitan and Metropolitan District Railways, who produced a lot of this volutile liquid condensed from their gas under pressure, but the great difficulty was to manufacture it. It contained a large quantity of permanent gases, and also a large quantity of olefines mixed with benzol. Benzol then was a valuable product, but when extracted from the hydrocarbon liquid it was extremely dangerous to manufacture into aniline. The only thing one could do was to mix it in small proportions with benzol derived from coal-tar naphtha, otherwisê there would be a burst. As soon as benzol went down in price the whole process was stopped. It was too risky. This process was interesting from a chemieal point of view, because one derived from the manufacture of American gas oil, which consists almost entirely of hydrocarbons of the paraffin series, a series of 
hydrocarbons of quite different constitution, viz., olefines and a lot of the benzene series. I think what Mr. Ballantyne suggested as to the testing of exhaust gases is all for the good of the industry. If manufacturers of motor cars would employ skilled chemists their money would not be wasted. There are other materials besides these hydrocarbons which might be analysed, but in these matters you had better not go in for an amateur chemist. It is better to have a highly trained chemist. Mr. Blount will agree with that probably.

Mr. W. J. A. Butterfield :* It would be possible to crack petroleum residues so as to produce a fairly uniform grade of motor spirit. What the yield would be it would be difficult to forecast. The product would not have a uniform chemical composition, which was what the early experimenters were aiming at in the production of benzene or benzol. But it could nevertheless distil or volatilize within a very limited range of temperature, and be of approximately as high a calorific power as petrol and wholly combustible.

In regard to dissolving any solid substance in petrol, Ineed not, in view of previous comments, say anything about picric acid, but if any solid substance had to be dissolved in petrol before combustion, such a material as naphthalene presents itself as most suitable. I do not know absolutely its degree of solubility in petrol, but it is freely soluble in the higher fractions of petroleum. If such a solution were tried it would answer in respect of complete combustibility, high calorific value and cheapness, but it would fail on the score of lack of uniformity of volatilisation or distillation. It is in that latter respect that the figures given by Mr. Blount for various petrols are so interesting in showing that, on the whole, the commercial petrols are highly uniform in their range of distillation. I suppose what has to be avoided mainly is a large quantity of the residues distilling above $133^{\circ}$, or even of the portion distilling above $120^{\circ}$. An apparatus for testing the volatility of petrol on the lines of that exhibited this evening by Mr. Baillie seems to be less useful than the distillation tests because of the unknown quantity or small amount left ( $I$ think it was said one-tenth or onetwentieth of the total volume). We do not know from this otherwise valuable test what that residue is or how long it would take to volatilize. For a rapid and, up to a point, very useful examination

* Some additional observations by Mr. Butterfield will be found on page 319. 
of petrol, the apparatus, however, must be most valuable, and I would express my admiration for its arrangement and design. One point in regard to Mr. Blount's table is the uniformity of the calorific value which it shows. This is indeed remarkable, but it is also a remarkable fact that petroleum of all grades and from all known sources in the world is comparatively uniform in regard to calorific power. It is quite a contrast to any other natural fuel in this respect. The surprising thing to me is that, being derived, as the petrols undoubtedly must be, from a large variety of different natural petroleums, they should have nearly the same specific gravity and nearly the same range of distillation. I should have expected that for the same range of distillation the specific gravity would have been much more widely different than it is.

Mr. Charles WheELer: Mr. Brewer has referred to the evaporation test, and has expressed the opinion that that test is of more practical value than the distillation one. It is an opinion with which I am in full agreement, and the experiments I have carried out with petrol have been on these lines. Mr. Blount, in reading the last paragraph but one of his paper, observed that the opinion expressed therein was an obvious truism. I wish it were an obvious truism, but unfortunately it is not. I refer to this-petrol of recognised brands is fairly uniform in quality, and there is no great difference, so far as his tests show, between three of the recognised brands. The tests I have carried out confirm this. In a certain firm with which I am connected it was my business to draw up a specification and invite tenders for petrol, and I followed very closely the lines laid down by Mr. Blount in his paper. Now I found myself in a very peculiar position. Some four firms quoted prices and submitted samples. The prices they quoted were the same, and the samples they submitted all complied with the specification. I kept the latter purposely wide, for the reasons given by Mr. Blount. The problem I then had to tackle was, "How to place the order, and on what recommendation?" I carried out an evaporation test, the result of which $I$ will give in the form of a diagram. (Fig. 2.)

The specific gravities shown at the ends of the curves in the diagram indicate the density before and after test. It will be seen that in the one ease there is a variation of $\cdot 020$ and in the other of $\cdot 003$ only. Each spirit tested worked satisfactorily in actual practice. The spirit represented by the upper curve would probably appeal to the driver of a motor vehicle, as owing to the fact that a high percentage of the constituents are very volatile, starting-up would be 
comparatively easy; but as the result of a discussion with an experienced friend, I am inclined to think that the spirit represented by the lower curve would be the better investment, as the spirit is not only heavier, but is of more uniform quality (witness the initial

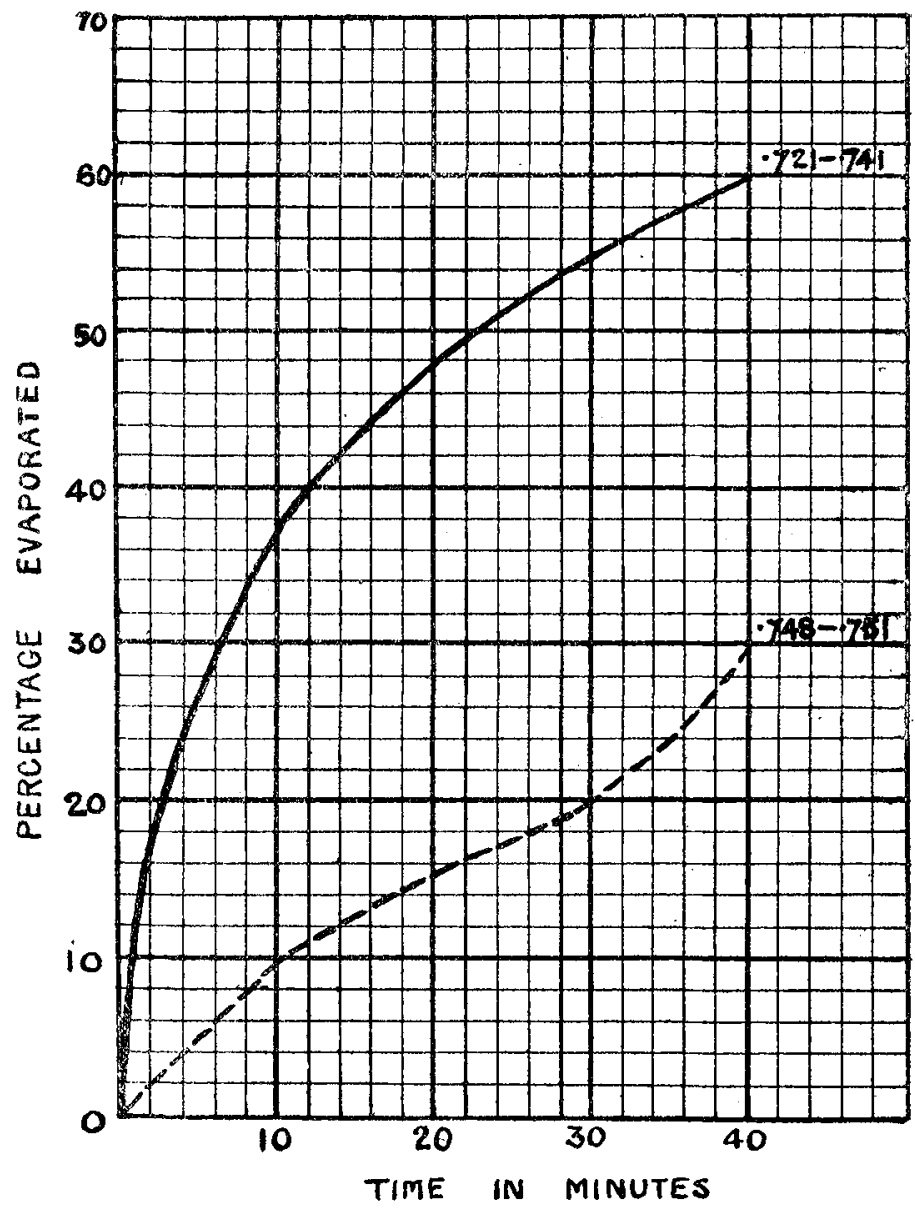

FrG. 2.

and final S.G.), and probably has a higher calorific value. I believe I interpret $\mathrm{Mr}$. Blount correctly when I say that I understand him to lay down that when petrols will work efficiently that spirit which has the higher calorific value would be the better investment. I shall be glad if I may be informed whether my view, that the spirit 
represented by the lower curve is the better value for money, is a correct one.

I note with pleasure that the amount of carbon-monoxide in the exhaust gases from motor cars is going down, and that despite the fact that the specific gravity of petrol has gone up. This is strong testimony to the steady but marked improvernent that is going on in the design of carburettors.

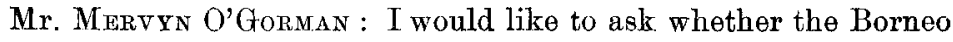
oils alluded to might be expected to produce more tar in the cylinder than others. I have made a considerable use of Borneo oil and have had no such trouble. Under what circumstances might one expect to find tar on the piston top after using this oil for some time?

As regards improving petrol, I had reason a year ago to make enquiries as to whether there was any mixture known that would increase the power of a motor car engine. I wanted this information in connection with the regulations for the O'Gorman Trophy at Brooklands. The best information I could get was that there existed nothing practical of the kind at the time. Since the regulations were issued the opinion has sometimes been held in the Press that it was wicked to allow a competitor to gain any advantage by the simple process of doctoring the fuel, but having made careful enquiries I was satisfied that there was no simple process which would add in any way to the power; and that if one were discovered which worked, then it deserved to be fully rewarded. Accordingly no restriction whatever was made, and, as I expected, nobody used any "dope." Oxygen could be used, of course, but in that particular eontest it would not be of much advantage, indeed it would be almost ruinous to a driver's chances to carry enough oxygen in steel cylinders to make any significant difference in 100 miles. The comparison which would have been possible had various chemicals been used would have given such an attempt an increased scientific interest. I should have liked to have got Mr. Ballantyne to give briefly, as an addendum to his paper, a description of the chemistry of his method of analysing exhaust gases. It would be small trouble.

'There is a published repurt in the Proceedings of the American Soo. of Merhan. Engineers, Trans. 27, pp. 193-227; Discussion, pp. 227-331, 1906, read Dec. 1905, which taken in connection with Mr. Baillio's remarks is very interesting. Very few people know that Mr. Durley described what must be considered as a remarkable property for a 2-inch hole. His experiences seem to 
show that a 2-inch hole in a large plate differs from every other size of hole in this respect, that if you try to force air through any hole rather smaller than a 2 -inch, the amount of air that flows through increases with the pressure; and so also does the coefficient of discharge, but as you approach towards 2-inch diameter you get a smaller variation of the co-efficient and the variation becomes less and less until the 2-inch hole is arrived at, when the co-efficient is practically constant, and therefore the pressure difference is a measure of the volume. This of course makes for an easy way of measuring a difficult thing, viz., the amount of air going through a hole. That experiment should be carried out a stage further, because Durley only tried it up to 6-in. difference of water gauge on the two sides of a plate, and much more is wanted for motor car purposes.

I have heard in conversation with Dr. Watson that he has made some experiments in co-relating air volume per second and the air pressure on opposite sides of plates (with various sizes of holes in them), and when such results are made public they will, inasmuch as they were made for the purpose of being used in connection with motor car engines, be of far more use and interest to the Institution than Durley's experiments of 1905. I should like to conclude by joining in the chorus of thanks to Mr. Ballantyne and Mr. Blount.

Mr. J. S. StAFFord : As a practical motorist and one who has done a lot of testing of motor cars under circumstances painful to recollect, I would like to refer to the suggestion that has been made with reference to the testing of the exhaust gases of motor cars with a view to determining the processes going on in the carburetter. This has always been an attractive subject to me, and I am pleased to see that one of the lecturers to-night is of opinion that this is well within the compass of any intelligent man. Looking at the Table, it is a most significant thing that, taking the No. 14 example and comparing it with No. 4, we have there two spirits that vary and are diametrically opposed to one another in one respect. In the first we have a spirit which distils in steady steps, and in the other one which goes over all at once. When a man is testing a car it would be of yreat assistance to that man if, knowing the character of the spirit he is using, he could test, by means of the exhaust gases, what was happening in the engine and carburetter. It would be of immense practical value, and I would welcome such an apparatus as would place in the hands of the heads of testing departments the power to do this. In my old 
testing days it would have been a thing I should have jumped at. I had hoped to refer to some interesting points in the papers, particularly the manner in which light spirit helps evaporation, and the influence of even so small a proportion as 20 per cent. in conferring adequate volatility and combustibility on the remaining less volatile fuels. A spirit which might have been obtained by the snixture of a light gasoline aud heavy spirit-something which could not be detected by the hydrometer-might be manufactured, showing that a light spirit can help the heavier spirits to come within the compass of use on a motor car. This is a thing of great interest to me.

The chemical effect that a compound such as picric acid, on the one hand, as a solid, and then of acetylene gas, on the other, has upon petrol when dissolved in it, is also very interesting. The dissolving of such substances in petrol for the purpose of increasing its power, although at the moment it does not appear to be of practical interest to motorists, has great possibilitios before it. It is possible that a fuel which could be used might be produced by cracking that could not be employed in cars except by the methor of putting some gas into it in solution. It might be that the dissolved substance would have the effect of a detonator and give the other portion of the fuel a start. 


\section{COMMUNICATED.}

The following written contribution has been received :-

Mr. W. J. A. Butterfield: In regard to the saturation of petrol with acetylene, referred to by Mr. Ballantyne, he appears to attribute to petrol a rather lower solubility for acetylene than Berthelot's researches suggest. Berthelot found that one volume of "benzolene" at $18^{\circ} \mathrm{C}$. dissolved four volumes of gaseous acetylene, but obviously the quantity of acetylene which petrol is capable of containing is too little to be of much value as an addition to the petrol. Indeed it is not clear what advantage is to be expected from any such addition since a mixture of acetylene and petrol vapour is of lower calorific value than that of an equal volume of undiluted petrol vapour. A process for enhancing the calorific value of acetylene, where that gas is required for heating or cooking purposes or for driving small motors, consists in the carburetting of the acetylene with the vapour of petroleum spirit, and a very marked gain in calorific value is thus attained. The real advantage which acetylene might afford in certain conditions is that it is gaseous at all ordinary temperatures. If it were desired to take advantage of this quality there are other bodies which are superior to petrol as solvents of acetylene. For instance, alcohol dissolves six times its volume of gaseous acetylene, while acetone dissolves twenty-five times its volume under ordinary pressure. A solution of acetylene in acetone, under about ten atmospheres pressure, is known in commerce under the name of dissolved acetylene, and while generally only used for lighting purposes, it will serve as fuel for small motors, but in respect of portability such a solution is, for a given power or calorific value, far inferior to an equal volume of petrol.

Mr. JoHN OKrLL: In his instructive paper, Mr. Blount mentions that the determination of the calorific value of the petrols he experimented with was a matter of some little difficulty. The bomb calorimeter is no doubt an excellent piece of apparatus for determining the calorific value of fuels, its high first cost being perhaps the greatest drawback to its more extended use; moreover, it is not particularly easy to manipulate. 
For the former reason, I was led to try to devise a simple apparatus by which accurate results could be obtained, and as the results so obtained compare favourably with those of Mr. Blount, I thought a description of the apparatus $I$ used would be of interest. The apparatus comprises :-

A Dowson calorimeter as used, without any alteration, for determining the calorific power of ordinary town's gas. A small blowlamp (auto-torch) modified slightly so as to give a vertical Bunsen flame, the air supply being adjustable, and a Roberval balance.

To carry out a test, the blow-lamp is filled with the petrol to be tested, and, resting on one scale pan of the balance, partly balanced by weights on the other scale pan, is allowed to burn in the calorimeter until a uniform difference in temperature between the inlet and outlet water to and from the calorimeter is obtained.

At the instant when the lamp side of the balance lifts off a fixed support, the water flowing from the calorimeter is diverted into a beaker. A weight of $(01$ of a pound is then placed on the lamp scale pan; this brings it down on to the support, the flow being diverted from the beaker, when the lamp side of the balance again just lifts off the support, the water collected being the amount heated by the combustion of 01 of a pound of petrol.

Taking "shell" spirit: S.G. 718 as one example of petrol tested, the results are given in the accompanying table:-

\begin{tabular}{|c|c|c|c|c|c|}
\hline $\begin{array}{l}\text { No. of } \\
\text { Test. }\end{array}$ & $\begin{array}{l}\text { Weight of } \\
\text { Water } \\
\text { Cireulated. }\end{array}$ & $\begin{array}{l}\text { Time in } \\
\text { Seconds to } \\
\text { bur: } \cdot 11 \text { lb. } \\
\text { of Petrol. }\end{array}$ & $\begin{array}{c}\text { Mean Inlet } \\
\text { Temperature } \\
\text { "C. }\end{array}$ & $\begin{array}{l}\text { Mean Uutlet; } \\
\text { Temperature } \\
{ }^{\circ} \mathrm{C} \text {. }\end{array}$ & $\begin{array}{c}\text { Calorific } \\
\text { Vilue } \\
\text { B.Tr.U } \\
\text { per lb. }\end{array}$ \\
\hline 1 & $\begin{array}{c}\text { C.O. } \\
9,200\end{array}$ & 531 & $11 \cdot 450$ & $17 \cdot 000$ & 20,200 \\
\hline 2 & 9,800 & 571 & $11 \cdot 450$ & $16 \cdot 700$ & 20,370 \\
\hline 3 & 8,000 & 450 & $11 \cdot 050$ & $17 \cdot 383$ & 20,070 \\
\hline 4 & 8,480 & 478 & $11 \cdot 015$ & $17 \cdot 012$ & 20,150 \\
\hline
\end{tabular}

Separately tested, 01 of a pound of petrol gave 5 c.c. of water products, i.e., $1 \mathrm{lb}$. of petrol gives 500 grammes of water $=1.10 \mathrm{lb}$, hence, $1 \cdot 10 \times 966^{\circ} 6=1,060$ B.Th.U. must be deducted from the above (high values) to determine the "low" calorific value of the fuels. 


\section{REPLY TO THE DISCUSSION.}

Mr. Baldantyne : I shall endeavour to answer very briefly some of the questions which have been raised, and leave the others to be answered in writing. I thank you, gentlemen, for listening so carefully to the paper and treating it so gently. I am sure Mr. Blount only meant as a pleasantry what he said about the amateur chemist; Mr. Blount is as much impressed as I am with the necessity of doing what is in our power to assist the profession in which you gentlemen are engaged, viz., that of automobile engineering, by improving the performance of cars in the matter of the emission of objectionable exhaust gases.

I shall be pleased to explain this method of gas testing-a method which can be employed by untrained people-to anyone interested in it. Of course, one cannot get up a knowledge of chemistry by learning a few rule of thumb methods, but this is a case in which rule of thumb methods suffice; it is a case in which, for the particular purpose in view, a knowledge of chemistry is unnecessary.

Mr. Baillie and other gentlemen have referred to the formation of tarry deposits in the cylinder. I think Mr. Brewer has hardly understood the nature of the remarks in the paper on this point. I have explained that carbonaceous deposits may be formed from petrol or heavier petroleum spirits, but not merely from the substance being exposed to the heated walls of the cylinder. Such deposits may also be produced from lubricating oil when it is used in excess. As a rule, however, tarry deposits are due primarily to the free carbon which is formed in a rich combustible mixture, when the excess of petrol spray and vapour present is subjected to the high temperature of the explosion; the finely divided carbon liberated then adheres to any lubricating oil present on the inner surfaces of the cylinder or piston, and so produces a tar-like substance. The most likely way of getting the requisite high temperature is not from contact with heated cylinder walls, because the temperature is only, relatively, low there; it is extremely high, however, in the burning mixture.

Mr. Baillie has also eriticised, very mildly, the suggestion that rrogress eannot be made unless analysis of the exhaust gases comes 
to our aid. His suggestion is on a level with that of a doctor who might maintain that that which goes into a patient furnishes the data for a diagnosis of the case. I quite recognise that this is not altogether a drawing-room illustration, but a doctor in his diagnosis does not depend entirely on a knowledge of the medicines he puts into the patient. Although you might ascertain the relative proportions of petrol and air used, by the method shown to us by Mr. Baillie, you would not get any idea from that of defects due to improper fitting or imperfect combustion. Both methods are extremely valuable; they should both be used. You cannot ascertain the suitability of a steel for any particular purpose by determining the pereentage of phosphorous or sulphur only; you must know hoth before you can determine the quality of the steel. I congratulate. Mr. Baillie upon his apparatus, but I think it might be improved in one or two small respects. For the purpose it is designed to meet, it is very good indeed, and not likely to be put out of order.

Mr. Brewer rather objected to my opening statement about the present high price of petrol ; I leave consumers of petrol to judge upon this matter. I entirely agree with what he has said about the cost not being excessive as it stands, taking into account all the charges connected with its preparation and distribution. The price is sufficiently high, however, to offer an inducement to others to invent new fuels. A question was asked by Mr. Brewer with regard to a process of precipitating wax and getting a fuel from paraffin oil, suitable for motor cars. All I can say to that is that there is no wax in paraffin oil and nothing to be precipitated. Paraffin oil is extremely refractory. We know of very few gentle processes of dealing with it, so as to affect its chemical or physical properties. The methods of treating it at higher temperatures are not gentle; such processes are now more or less of an academic nature, and there is no inducement to any inventor to work upon these lines.

Mr. Butterfield has referred to the dissolving of solid substances in petrol. Naphthalene he has instanced as being a promising material. To dissolve naphthalene has been tried and patented, but there is this objection to it, that naphthalene, though a very good fuel, canaot be added to petrol without giving trouble. If added in sufficient quantity to be worth considering, then by evaporation it produces erystals which choke up the jet. Naphthalene crystals take an extremely bulky form, and if any of these crystals are 
formed they choke up the jet and trouble ensues. If you use only a small quantity of napthalene the quantity is so small that it is not worth proceeding with.

Mr. O'Gorman has somewhat confused the cracking of Borneo oil and the use of Borneo spirits. We get an admirable motor spirit from Borneo oil. In discussing the question of cracking these oils I mentioned that it produces tar. When you take Borneo spirit and burn it with plenty of air, however, you have no tendency to produce carbon. Mr. O'Gorman has also referred to the absence of any method of treating petrol so as to increase the power of the engine. I have never come across a successful method of treating fuel to produce that effect, they have all resulted in failure. The best fuel at present is petrol undefiled, and the best method of using it is to adjust the carburetter so as to minimise the amount of carbon monoxide in the exhaust.

I think a description of the method of analysis of exhaust gases was given in broad outline as an appendix to Mr. Dugald Clerk's paper. That will, perhaps, answer Mr. Stafford's remarks.

$\mathrm{Mr}$ Butterfield, in his written contribution, alludes to solutions of acetylene in alcohol and acetone. My experience with such solutions, however, is that, when used in a motor, they fall far short of ordinary petrol in respect of power developed-leaving their prohibitive cost entirely out of the question.

Mr. BLount : It is incontestable that some direct method of measuring the volatility of petrol apart from the indirect method of fractional distillation is most important. It is not to be supposed that the method I have used is the only possible method; it was simply adopted because it is a well-known process, susceptible of great accuracy in proper hands. It is one which large buyers can adopt; it will be very diffeult to displace a method of that sort. To begin with, I may say that in regard to the mode of distillation, it is important to ensure that the results of distillation may be concordant. I will add the details of the method to which I have referred in my paper so that anyone wishing to draft a specification may use the apparatus which I have found effective. It seems to me that it is time that standardisation of some kind was introduced into such matters.

With regard to $\mathrm{Mr}$. Wheeler's remarks, I agree that the lower curve shows a smaller change in specific gravity during volatilisation under the conditions imposed, but I doubt whether any positive deduction can be drawn unless both curves are extended. 
I have a note from Mr. Butterfield saying that he wanted me to point out the proportion of air required for complete combustion of these different petrols. He suggestod that this information should be ascertained and tabulated, remarking that it would add to the value of the information given in the papers if such could be formulated. As this investigation would necessitate an organic analysis of all these samples I am afraid that in the present congested state of my work I am not prepared to undertake it.

I am interested to learn that by a simple adaptation Mr. Okill has succeeded in utilising one of the continuous type of carburetters for the determination of the heat of carburation of petrol. As is well known there are certain practical difficulties in using this method, chiefly arising from the need of securing complete combustion. The results go to show that this desirable end has in this case been secured.

The Presiden's: We are all very much indebted to Mr. Ballantyne and Mr. Blount for thoir able and interesting papers. There are many points $I$ would have liked to have spoken on, but at this late houx I will content myself with thanking the authors for the useful information they have conveyed to us, and asking the meeting to pass a hearty vote of thanks both to Mr. Ballantyne and Mr. Blount.

The vote of thanks was carried with acclamation and the proceedings terminated. 


\section{APPENDIX A.}

\section{$\longrightarrow$ \\ DESCRIPTION OF THE METHOD OF EXECUTING AN EXHAUST-GAS ANALYSIS.}

BY HORATIO BALLANTYNE, F.I.C., F.O.S.

In response to the desire expressed by several members of the Institution, I give below a description of the method of executing an exhaust-gas analysis in the apparatus of Macfarlane and Caldwell.

Gas analysis of this kind is based upon the principle of bringing a measured volume of the gas to be analysed successively into contact with a series of solutions, which have the power of absorbing cortain of the gaseous constituents present. For example, caustic potash solution absorbs the carbon dioxide $\left(\mathrm{CO}_{2}\right)$, and that only; from the residue, alkaline pyrogallol solution absorbs the oxygen $\left(\mathrm{O}_{2}\right)$; and from the residue cuprous chloride absorbs the carbon monoxide (CO). By observing the diminution in volume suffered by the gas at each treatment, the volume of the particular constituent absorbed is ascertained. If, for example, 50 c.c. of the sample be used for the analysis, and the volume after treatment with caustic potash solution be $44 \cdot 8$ c.e., the difference, amounting to $5 \cdot 2$ c.c., represents the volume of $\mathrm{CO}_{2}$, which has been absorbed by the potash from the 50 c.c. of gas taken, and the percentage (by volume) of $\mathrm{CO}_{2}$ is $5 \cdot 2 \times 2=10 \cdot 4$. It is usual to express all results as percentage by volume.

The Macfarlane-Caldwell apparatus is shown in the accompanying figure (Fig. 3).

It consists essentially of a graduated "gas burette," G, in which the volume of the gas under examination can be observed at intervals; a counterpoised, adjustable, mereury reservoir, $\mathrm{C}$, by raising or lowering which gas may be driven out of, or drawn into, the burette, $G$; and a "gas pipette," M, containing the absorbent 
solution, with which the gas driven out of the gas burette is to be treated. In ordinary practice four gas pipettes are used, containing respectively the following solutions:-(1) caustic potash (50 grammes of caustic potash dissolved in 100 c.c. of water), for

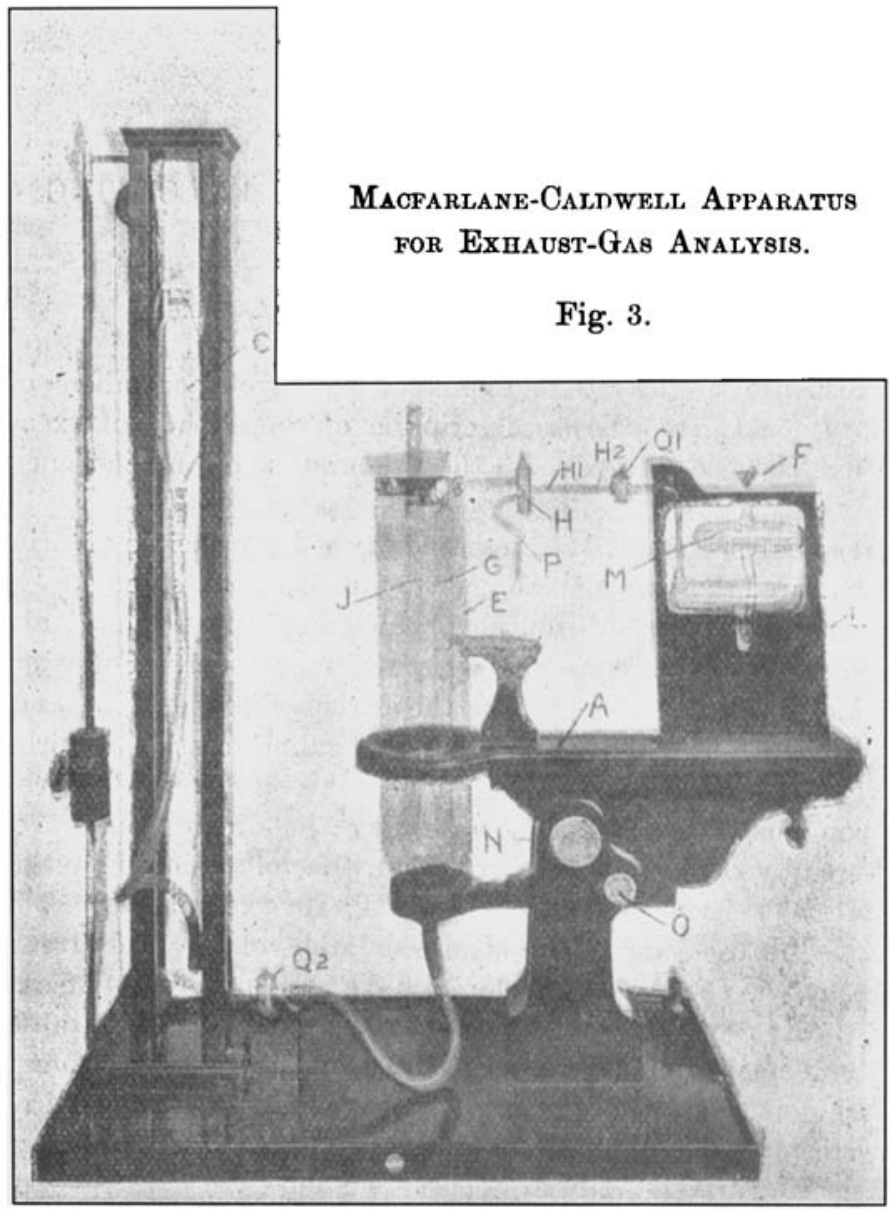

the absorption of $\mathrm{CO}_{2} ;(2)$ alkaline pyrogallol $(5$ grammes of pyrogallic acid and 50 grammes of caustic potash dissolved in 100 e.c. of water), for the absorption of oxygen; (3) acid cuprous chloride solution (used), for the absorption of the bulk of the carbon monoxide; and (4) fresh acid cuprous chloride, for absorb- 
ing the last portions of the carbon monoxide. The two cuprous chloride solutions are necessary because, when the quantity in one pipette has, in the course of two or three analyses, absorbed a few cubic centimetres of $\mathrm{CO}$, it loses its power of removing the $\mathrm{CO}$ completely from the gas, and as much as 0.5 per cent. or more of this constituent may remain unabsorbed. A second treatment, using fresh cuprous chloride solution, enables this portion to be absorbed. The used cuprous chloride solution is only relied upon in further analyses for extracting the major portion of the $\mathrm{CO}$, and preserving the fresh solution from early deterioration. The cuprous solution is prepared by dissolving 36 grammes of cuprous chloride in a mixture of 100 c.c. of water, and 150 c.c. of concentrated hydrochloric acid. Both cuprous solutions, when not in use, are kept in bottles half filled with copper turnings, otherwise the oxygen in the air would rapidly oxidise them to the cupric condition. Each gas pipette is mounted on its own wooden frame, L, the base of which can be slipped into a groove on the top of the rocking frame, $\mathrm{A}$, until the capillary tube, $\mathrm{H}_{2}$, of the pipette comes into contact with the capillary tube, $\mathrm{H}_{1}$, connected through the two-way stop-cock, $\mathrm{H}$, with the gas burette. The gas burette, G, and its open limb, J, are enclosed within a water jacket, E, which prevents changes of temperature during the analysis, and renders unnecessary all corrections for temperature. The rocking frame, $A$, can be caused to oscillate about the pivot, $N$, but when at rest is held in the position shown by means of the sliding pin, $O$.

To prepare the apparatus for use, the gas pipette, $\mathbf{M}$, and its frame are withdrawn and mercury is poured into the reservoir, $\mathrm{C}$, until the gas burette, $G$, is filled completely up to the stopcock, $\mathbf{H}$, no air being entrapped in any part of the rubber connections. The stopcock, $Q_{2}$, keeps the movement of the mercury under control.

The analytical operation is carried out as follows: A small quantity ( 2 c.c.) of water, preferably saturated with exhaust gases, is drawn into the gas burette by connecting a piece of rubber tubing to the eapillary, $\mathrm{H}_{1}$, immersing the tubing in the water, lowering the reservoir, $O$, and then opening the stopeocks, $Q_{2}$ and $H$. The 2 c.c. of water in G must completely fill the tube from the top of the mercury to the capillary $\mathrm{H}_{1}$. The latter is now connected by means of rubber tubing, filled with water, to the vessel containing the gas to be analysed-say a copper cylinder provided with inlet and outlet stopcocks. The two-way cock, $\mathrm{H}$, is set so as to communicate with the tube, $\mathrm{P}$, and the gas sample is caused (e.g., by admitting 
water into the copper cyliader from below) to blow through the rubber tube and the tube, $P$, into any suitable receptacle, for a few seconds, to expel the water and any entrapped air bells from the connecting tube. The cock $H$ is now turned off, the reservoir is lowered, and by carefully opening the cocks $Q_{2}$ and $H$ the sample is allowed to flow into the gas burette, $G$, until the latter contains abont 49 to 50 e.c. The cocks are closed, the sample cylinder is removed, and by raising or lowering the reservoir, $\mathrm{O}$, the meroury is brought to exactly the, same level in the two limbs $J$ and $G$, whereupon the volume of the sample is noted. Whenever, in the courso of the analysis, the volume of the gas in $G$ is to be read off, the mercury must first be brought to the same level in $G$ and $\mathbf{J}$ (the gas being then under atmospheric pressure), and the water must be allowed to drain down in $G$ for two minutes.

There is now a definite known volume of the sample (say, 49.5 e.c.) enclosed between the stopcock, $H$, and the water in $G$. A pipette, M, filled with caustic potash solution to about one-eighth inch above the bottom of its upper bulb, is slipped into the rocking frame, A, until the capillary tubes, $\mathrm{H}_{1}$ and $\mathrm{H}_{2}$, are in contact (the joint being completed by about one inch of rubber tubing slipped over it); the cock, $H$, is carefully turned so as to communicate with $\mathrm{P}$, and by blowing into the pipette at $\mathrm{F}, 1$ or 2 c.c. of potash solution aro forced through the capillaries into any suitable vessel beneath $P$, for the purpose of carrying off any air-bells that might be lurking in the capillaries and the joint. The cock, $H$, is next closed, and by raising the reservoir, $\mathrm{C}$, and suitably manipulating the cocks $Q_{2}, H$, and $Q_{1}$, the sample in $G$ is cautiously driven over into the lower bulb of the potash pipette. All cocks are closed, the pin, $O$, is withdrawn, the frame, $A$, with all the apparatus upon it, is rocked upon the pivot, $N$, for 30 seconds, to bring the gas in $M$ suficiently into contact with the potash solution, and then, by a serios of reverse operations, the gas is drawn back into the burette, $G$, care being taken to prevent the potash solution from either stopping short of or entering the bore of the cock, $H$. The volume of the gas in $G$ is now observed (with the precautions mentioned above); the diminution represents the volume of $\mathrm{CO}_{2}$ in the quantity ، $(49.5$ c.c.) of sample taken for analysis. The potash pipette, $M$, is now removed, and replaced by one containing alkaline pyrogallol, the procedure being exactly the same as in the preceding treatment, excepting that the rocking must be continued for two minutes or more, because oxygen is not so readily absorbed as $\mathrm{CO}_{2}$ 
is. (It is easy to ascertain whether all the oxygen has been removed by noting whether any further diminution in volume occurs on ropeating the treatment.) The observed diminution in volume represents the volume of $\mathrm{O}_{2}$ in 49.5 c.c. of the sample. The residue of the latter is then treated in succession with used cuprous chloride solution (3 minutes' rocking), fresh cuprous chloride solution (2 mins.), and finally the caustic potash solution ( 30 seconds), the diminution in volurne giving the quantity of $\mathrm{CO}$ in 49.5 e.c. of the sample. The object of finishing off with the caustic potash solution is to eliminate any $\mathrm{CO}_{8}$ that might aceidentally have been set free by the acid cuprous liquid upon traces of the other re-agents adhering to the tubes. It is preferable, in the intervals of treatment, whilst the gas is in the burette, $G$, to clean out the capillary tube, $H_{1} P$, and the connecting rubber tube, by means of clean water.

From the results obtained as above, the percentages of hydrogen, methane, and nitrogen may be calculated by the method deseribed by me in Appendix B to the Paper read by Mr. Dugald Clerk before this Institution on "The Principles of Carburetting as determined by Exhaust Gas Analysis." (See Vol. II., Proceedings, p. 101.)

The Macfarlane-Caldwell apparatus is sold by Messrs. Baird and Tatlock (London), Limited, Cross Street, Hatton Garden, E.C. 
$(330)$

APPENDIX B.

\section{METHOD OF FRAOTIONAL DISTILLATION.}

By Bertram Blount, F.I.C.

The distillation is carried out in a Wurtz flask $8.0 \mathrm{~cm}$. in diam and with a neck $6.0 \mathrm{~cm}$. in length to the junction of the side tube, and having a capacity of $250 \mathrm{c.cm}$. The flask is connected with a Liebig condenser having an inner tube $75 \mathrm{~cm}$. long, $45 \mathrm{~cm}$. of which is water jacketed. The bulb of the thermometer is placed so as to read the temperature of the vapour just before the vapour enters the side tube. The flask is heated briskly with an Argand burner and the temperature at which the petrol commences to distil is noted, this point being taken when the liquid is really boiling, not when the first drop appears at the receiver.

On the temperature of the vapour approaching $100^{\circ} \mathrm{C}$. the heating is slackened and the temperature allowed to remain at that point for about two minutes, after which the receiver is changed.

The heating is thon continued until the temperature approaches $120^{\circ}$, when it is again slackened and the receiver changed exactly as at $100^{\circ} \mathrm{O}$.

The fraction $120^{\circ}-133^{\circ} \mathrm{C}$. is obtained as the previous fractions, the burners being turned out after keeping the temperature at $100^{\circ} \mathrm{C}$. for two minutes.

The whole of the distilling operation lasts about twenty minutes. 